\title{
Playing by a different set of rules
}

\author{
Florida's climate change plan is the latest in a wave of state strategies to limit greenhouse-gas \\ emissions. Mark Schrope asks whether stand-alone efforts could substitute or drive federal \\ action in the US.
}

\begin{abstract}
"The rules are different here" was an official slogan used in the 1980s to promote Florida tourism and as the butt of many jokes, but this year it is a more apt description of a new political climate since Governor Charlie Crist took office in January. In stark contrast to Jeb Bush, his predecessor and the president's brother, who preferred to keep climate change issues at a cautious distance, Crist, also a Republican, has embraced climate change as "one of the most important issues that we will face this century".

In July, Crist became the latest in a series of governors who, partly out of frustration with the US government's refusal to ratify the international Kyoto Protocol, have created state plans to limit greenhouse-gas emissions. Historically, such states-first action has often led to federal action on
\end{abstract} environmental issues. The landmark US Clean Air Act, the most recent version of which was enacted in 1970, for instance, followed from similar legislation in various states. Accordingly, there is growing international hope that state efforts, along with other complementary factors, could push the US to the level of leadership in the climate change arena that many countries have been longing for since the early days of the Kyoto Protocol.

California became the first state with a legally binding climate change plan in September 2006, at which stage several other states already had plans in place or in development that included ambitious emissions reduction goals (Nature 446, 114-115; 2007). That number has now grown to include almost half the states. Activity has been most focused in the West and the Northeast, but all regions have at least some participants. As well as state action, numerous US cities have enacted local plans, such as New York mayor Michael Bloomberg's strategy to reduce emissions by $30 \%$ by 2030 through over 100 initiatives, including hybrid taxis and energy-efficient buildings.

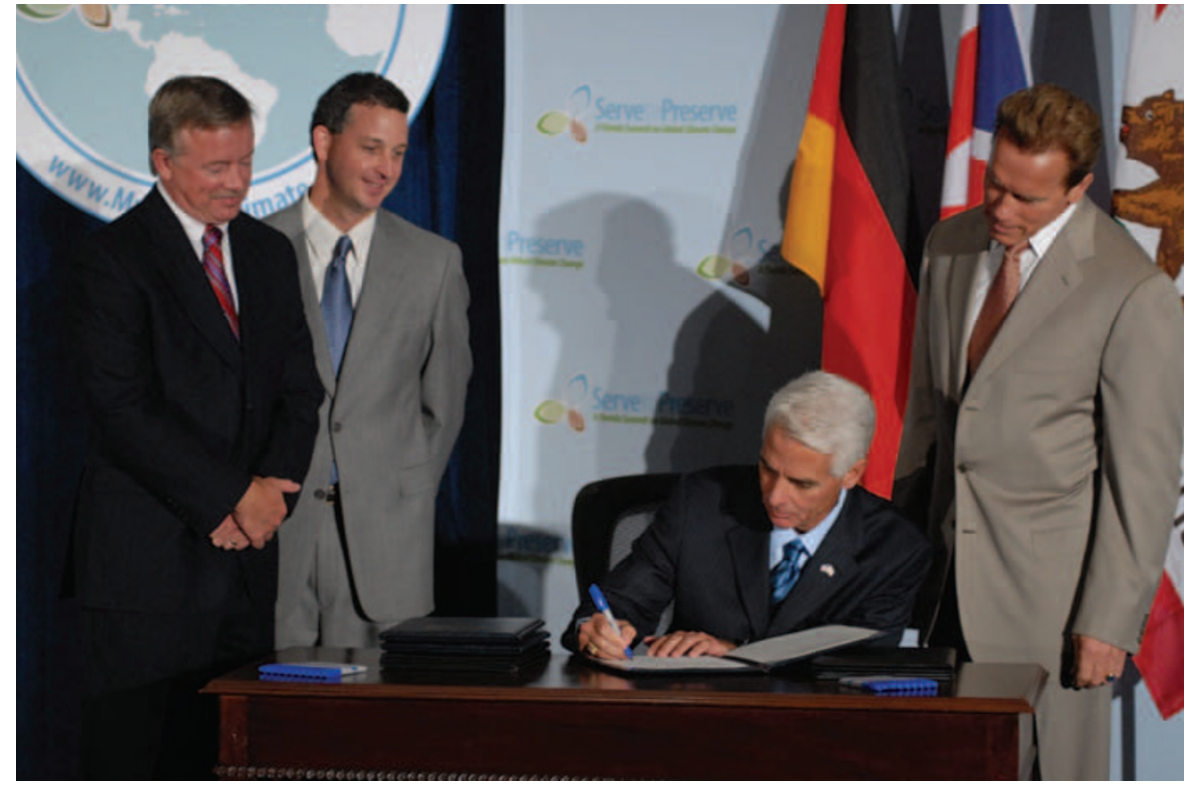

Republican governor Charlie Crist embraces climate change as one of the most important issues that we will face this century.

\section{SUFFICIENT SUBSTITUTE?}

Despite hopes for federal action, such regional plans are significant in their own right. Florida's 2000 emissions were about 300 million metric tons of carbon dioxide and California's emissions were nearly 500 million metric tons, which together exceed the emissions of the UK. The states with the four largest populations - Florida, California, New York, and Texas - have emissions roughly equivalent to Russia or India. Of those, only Texas is without a climate change plan in place. Federal legislation would almost certainly require individual state plans anyway, likely under the umbrella of the Clean Air Act, so the work now underway will facilitate rather than negate any future national strategy.

Though details vary, the overarching goals of plans to date typically include cuts to 1990 levels by about 2025 or better, and reductions of $75 \%$ or more from 1990 levels by 2050 . As the culmination of a Climate Change Summit he hosted in Miami, Crist signed executive orders on 13 July that set such goals for Florida. Participants included UK representatives and California's current governor, action movie star Arnold Schwarzenegger.

But even if all states roughly followed the templates established, it would reduce the country's total emissions to 1990 levels by about 2020 , compared with the target of 7\% below 1990 levels by 2012 called for under the Kyoto Protocol. Though many state plans are still voluntary, others have been legislated and include potential penalties, In California, for instance, fines for emissions violators are possible, but the governor also has the power to suspend targets if they are deemed to cause too much economic strain.

\section{STAND-OUT EFFORT}

Crist's orders also mandate nearterm leadership actions, including dramatic reductions for state agencies and departments. "I think the Florida plan is unique in terms of the amount 
of immediate action", says Thomas Peterson, executive director of the non-profit Center for Climate Strategies based in Harrisburg, Pennsylvania, "this really was a major leadership action by Governor Crist". In a commentary on the governor's plan, popular environmentally geared novelist Carl Hiaasen, who also pens an often scathing column for the Miami Herald, concluded that, "It's official: Charlie Crist is the un-Jeb". Crist told Nature he even saw and enjoyed An Inconvenient Truth, whereas Jeb Bush once joked with reporters that he refused to see it, favouring instead The Fantastic Four.

\section{It's official: Charlie Crist is the un-Jeb.}

\section{Carl Hiaasen}

Crist says he believes that Florida, with its nearly 2,000-kilometre coastline, is especially vulnerable to climate change impacts such as rising sea level, storm surges and hurricane strikes, which could severely threaten its economy, and so should be a leader in taking action. He credits California's Environmental Protection Agency former head, Terry Tamminen, also an important advisor to Schwarzenegger, as his most influential advisor on the climate change issue, but he also heard from a range of researchers and others before stepping out.

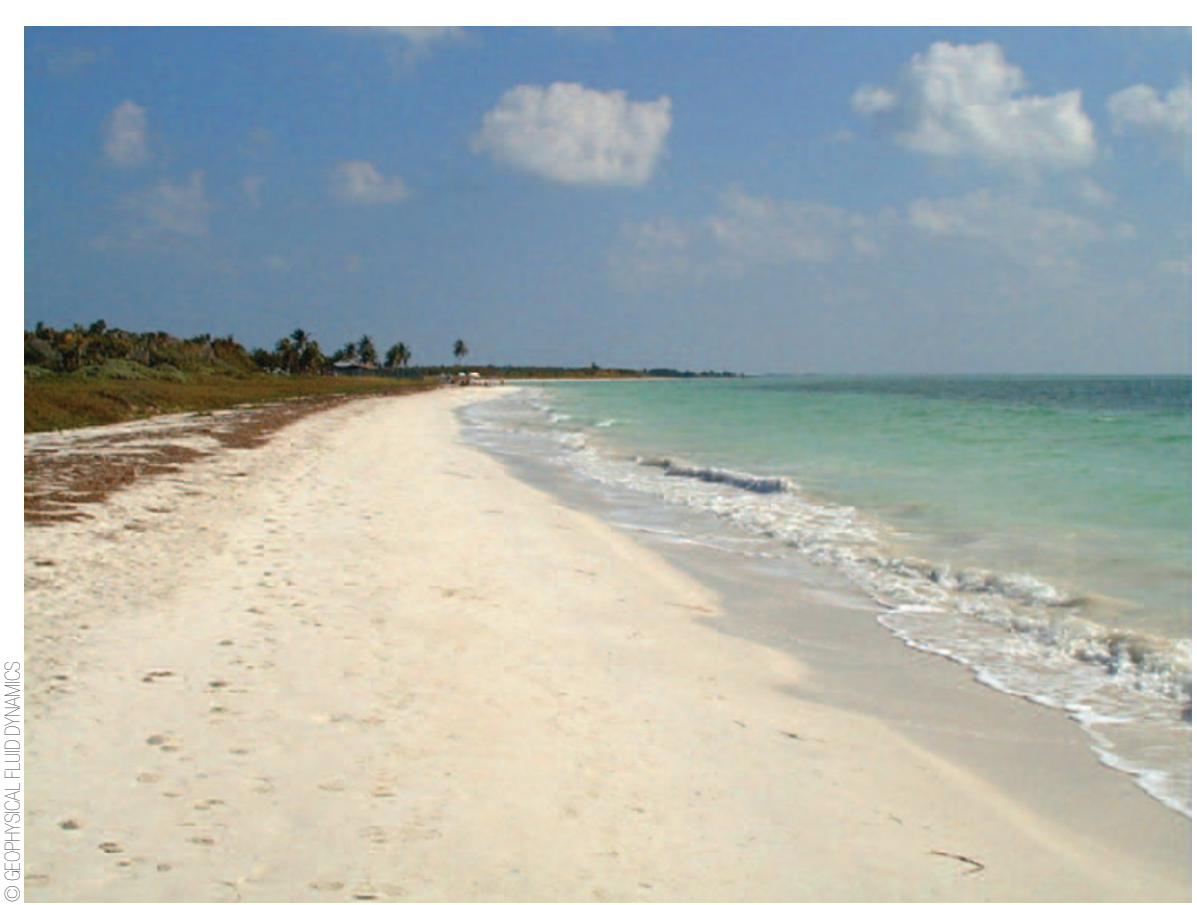

Florida, with its nearly 2,000-kilometre coastline, is especially vulnerable to climate change impacts such as rising sea level, storm surges, and hurricane strikes.
The cumulative impact of this advice brought Crist to what he refers to as a "sort of overused statement - a tipping point - where you realize we need to be doing something". And although all his fellow Republicans may not be similarly

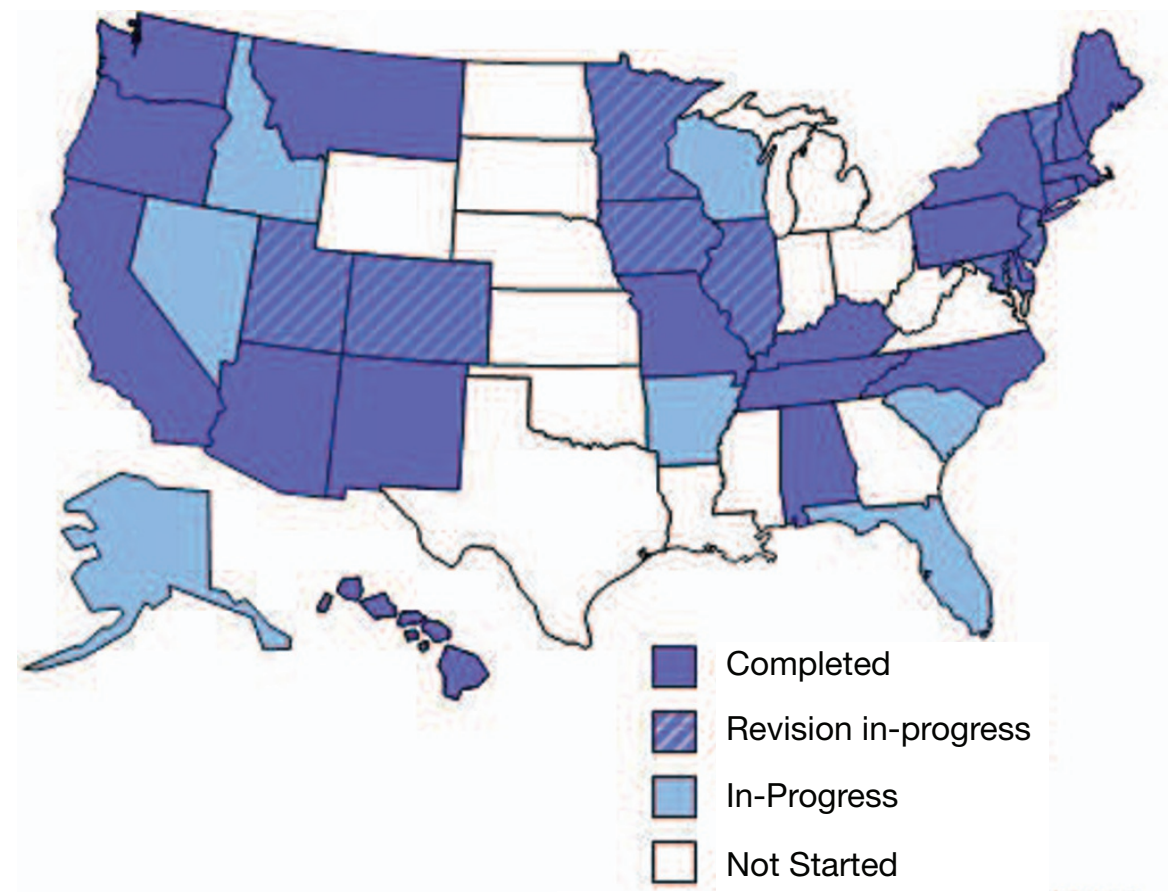

US states that have enacted plans or have plans underway to combat climate change.

convinced, Crist says that the reactions to his plans have been more positive than he expected. Peterson suggests that Crist's actions and the support he has received may not be as surprising as past, very public, political debates would suggest. Several of the states with plans in place or under development are led by Republican governors, though Republican state legislatures have not always proven to be as open to the work.

\section{INTERNATIONAL APPROVAL}

Internationally, the efforts by Florida and other states are viewed as a positive development, if not a complete solution. "It's absolutely commendable," says Suyata Gupta, an economist with the Asian Development Bank and lead author on the policies and cooperative mechanisms portion of the latest IPCC report. Gupta personally hopes that states, "will be able to accelerate the process at the national level," in part because she otherwise sees a number of barriers to maximum impact, even if every state participated individually.

One of Gupta's concerns is that if all states do not participate, laws in one state could simply lead companies to move some carbon intensive commercial activities to states with more lenient jurisdictions. Another problem is that individual states acting to meet their own targets are likely 
to duplicate research and development activities, reducing overall efficiency and slowing collective progress relative to nationally coordinated efforts.

Despite such concerns, international support for the plans is also evident through various collaborative efforts. Keith Allan, the British consul general for Florida, says that although the ultimate goal is national action, the UK has been strongly encouraging state actions in the US and offering help to those interested. Former Prime Minister Tony Blair signed an agreement with California to collaborate on climate change research and action, and the UK signed a similar agreement with Florida in July, as did Germany. Results of the Florida-UK agreement, for example, include a joint renewable energy conference scheduled for Miami in October, UK advisors meeting with Florida government officials, and collaboration between Florida and UK academic institutions to advance windturbine research.
At this point, just because of the number of states that have taken actions and been highly successful, Congress is beginning to wake up.

Thomas Peterson

\section{A WAVE OF CHANGE}

On the national front, Schwarzenegger and others have expressed hope that Florida's actions in particular will encourage other states in the more conservative South to enact their own plans. But, like most involved, he clearly views state actions as a step toward a federal plan, rather than a stand-alone solution. In fact, Schwarzenegger has said that California plans to sue the federal government in October if substantive emissions reductions are not forthcoming. Momentum does seem to be developing for such national action. "At this point, just because of the number of states that have taken actions and been highly successful, Congress is beginning to wake up," says Peterson. There are more bills now in the US Congress focused on climate change than ever before, though factors including high fuel prices and a recent Supreme Court decision that enables and even compels the Environmental Protection Agency to regulate carbon dioxide emissions have also been driving forces. And although this is undoubtedly due in part to the Democratic takeover of Congress last November, the recent actions of Republicans such as Crist suggest there may have been some movement in that direction regardless.

It's safe to say that countries actively engaged in climate change mitigation, particularly in efforts to establish postKyoto plans, are hoping that, in the US, as in Florida, the rules are indeed now different.

Mark Schrope is a freelancer writer based in Florida.

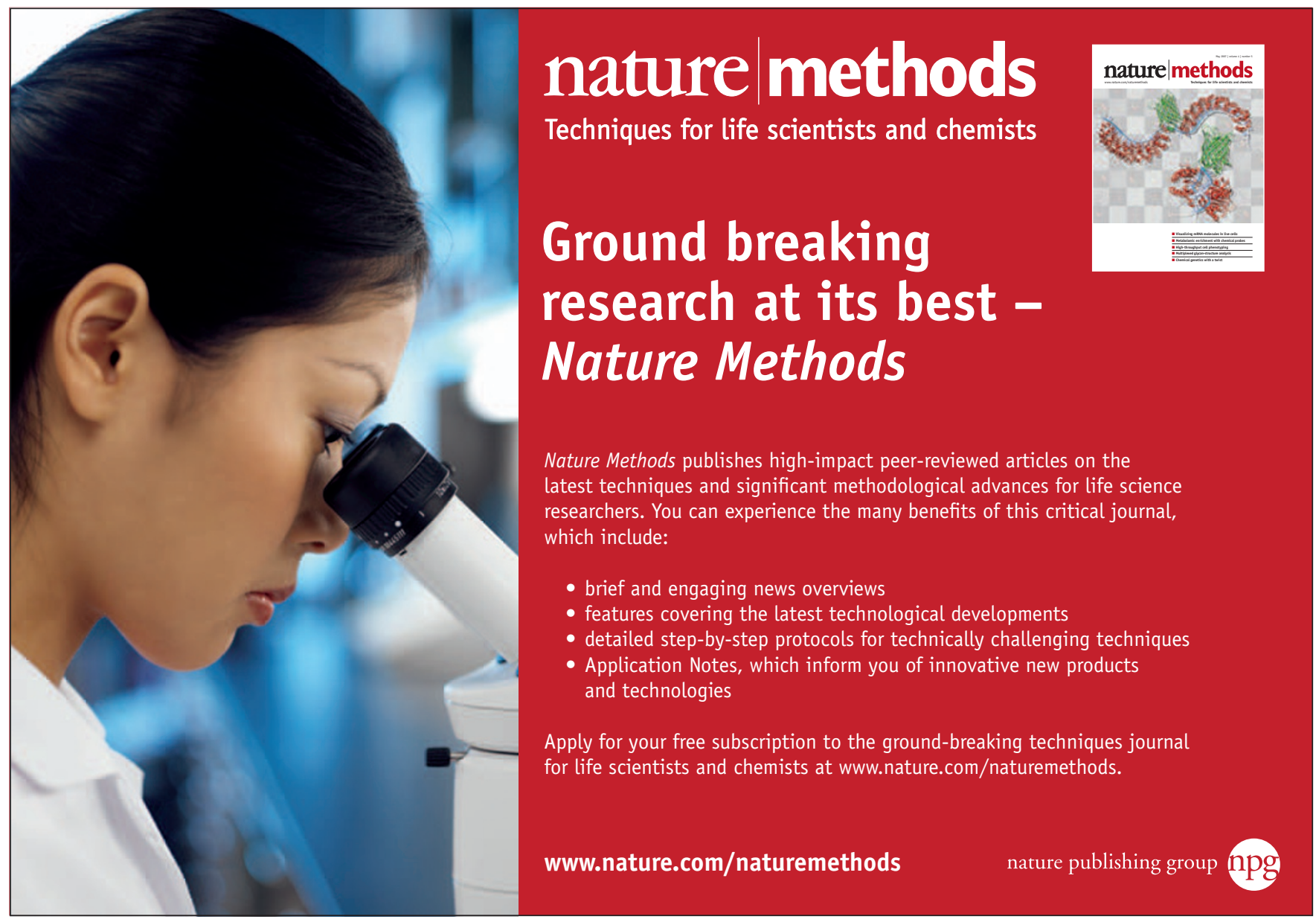

